NOTICIAS 


\section{A FACULDADE DE FILOSOFIA, CIÊNCIAS E LETRAS DE ASSIS}

\section{ALGUNS DADOS HISTÓRICOS}

A Faculdade de Filosofia, Ciências e Letras de Assis foi criada em 1957, através de Lei Estadual n. ${ }^{\circ} 3.826$, promulgada pelo Governador Prof. Dr. Jânio da Silva Quadros. Foi instalada a 16 de agosto de 1958. Na origem do projeto de criação, estava a proposta do então Deputado Estadual Santilli Sobrinho. Data da mesma época a instalação das Faculdades de Filosofia, Ciências e Letras de Marília, Araraquara, Rio Claro e Presidente Prudente que, com outros institutos de ensino superior, formam hoje a Rede dos Institutos Isolados do Estado de São Paulo, subordinada ao Conselho Estadual de Educação e à Secretaria da Educação, sob a Coordenadoria do Ensino Superior do Estado de São Paulo (CESESP) .

Em 1959, a Faculdade de Filosofia, Ciências e Letras de Assis começou a funcionar com as Licenciaturas em Letras. Sob a direção do Prof. Dr. Antônio Soares Amora, reuniu-se um grupo de especialistas no setor de línguas e estudos literários. Predominava, então, a concepção de transformar as recém criadas Faculdades de Filosofia em centros de pesquisa de alto nível, cabendo à Faculdade de Assis desenvolver o setor de Letras.

Paralelamente, foi construído e entregue em 1962 um primeiro prédio em "campus" próximo à cidade. Amplia-se o corpo docente e o setor administrativo. Em 1964, foi autorizado o funcionamento da Licenciatura em História. Em 1966, a Licenciatura em Psicologia. Em 1968, começou a funcionar a Licenciatura em Filosofia. Em meados da década de 60, não apenas a Faculdade de Assis, mas todas as demais Faculdades integrantes da rede dos institutos isolados, ampliaram os seus Cursos e Departamentos. A consolidação dos diversos cursos se dará nos anos 70 . 
Atualmente, se coloca na ordem do dia a definição do estatuto dos Institutos Isolados e sua integração no sistema de Ensino Superior do Estado de São Paulo. A proliferação das instituições privadas de ensino superior tem fortalecido a concepção dos Institutos Isolados de Ensino Superior como centros de ensino e pesquisa de alto nível, associados a programas de Especialização e Pós-Graduação.

\section{DADOS ATUAIS}

Na Faculdade de Filosofia, Ciências e Letras de Assis funcionam atualmente Cursos de Licenciatura em Letras, História, Psicologia, Filosofia e de Formação de Psicólogos. Conta a Faculdade com cerca de 1.300 alunos regularmente matriculados. Possui um corpo docente com mais de 100 professores (60\% em R.D.I.D.P.) e com um setor administrativo bem aparelhado. Com seus órgãos administrativos instalados (Conselho Superior e Congregação), conta com 6 Departamentos: Letras Modernas, Letras Clássicas, História, Psicologia, Filosofia e Educação.

Em seu "campus", com cerca de 120.000 metros quadrados, reunem-se três prédios, com todos os serviços essenciais ao funcionamento da Faculdade. A Biblioteca Central, instalada em prédio especial, possui um acervo de 35.000 livros e 16.600 volumes de periódicos com 1.400 títulos. Um programa de aquisição sistemática de livros e de assinatura de 120 periódicos tem sido regularmente mantido.

\section{DEFESAS DE TESES EM 1974.}

\section{SOCIOLOGIA}

Antônio Carlos Bernardo - Legislação e sindicalização: uma contribuiçãa à análise da industrialização brasileira (1930-1945) . 


\section{HISTÓRIA}

Anna Maria Martinez Corrêa - O Movimento de 1924 em São Paulo: um estudo das relações de poder.

Pedro de Alcântara Figueira - Historiografia Brasileira (1900-1930) .

\section{PSICOLOGIA}

Herma Brigitte Drachenberg - Aquisição de conceito de quantidade. Programação de um procedimento de "escolha conforme o modelo", para crianças.

Nivaldo Nale - Análise e avaliação de um curso programado individualizado de biologia.

Pedro Henrique Godinho - Aspectos da aplicação da potência nos testes estatísticos.

\section{LETRAS}

Aniceta de Nazaré Gonçalves Mendes de Mendonça - Significantes narrativos na ficção de Vergílio Ferreira.

Carlos Erivany Fantinati - O profeta e o escrivão: estudo sobre Lima Barreto.

Celso Pontara - Poetas Novilatinos da Academia dos Felizes de São Paulo (1770).

Eleusis Miriam Camocardi - Fernando Namora: um cronista no território da ficção.

Iumna Maria Simon - A rosa do povo; uma poética do risco.

João de Almeida - Introdução ao estudo das perífrases verbais de infinitivo na Lingua Portuguesa.

Leila Filinto Pinto de Almeida - A função das imagens sugestivas de animais na poesia de Dylan Thomas.

Letícia Zini - Permanenza e transformazione nel processo a Gesù di Diego Fabbri. 
Pedro Caruso - A obra poética de Duarte de Brito; edição critica.

Wilma Rodrigues - Bertolt Brecht: a reconstrução do mito de Joana D'Arc, visto por Seghers. 